\title{
Development and implementation of blended courses for Russian language teachers in Russia and abroad
}

\author{
Tatyana Malykhina ${ }^{1}$, Sergey Zolotykhin ${ }^{1 *}$, Lyudmila Larina $^{1}$, Alevtina Kuzmina ${ }^{1}$, and Tatyana Pravednikova ${ }^{1}$ \\ ${ }^{1}$ Kursk State University, Str. Radishchev 33, 305000, Kursk, Russia.
}

\begin{abstract}
The growing popularity of massive open online courses (MOOC) stimulates teachers to appeal to the theory and practice of this philosophy. MOOCs are aimed at widespread involvement of students, improvement of their progress in studies, implementation of the principles of lifelong learning throughout life, support and development of their professional competence, etc. However, the mechanisms for implementing of the basic principles of MOOCs philosophy remain a subject of discussion. The article deals with theoretical approaches to solving a number of MOOCs problems connected with the use of a training video. The models for using a video content described in the article are given in the context of a blended Russian language learning project implemented at Kursk State University.
\end{abstract}

\section{Introduction}

The cultural factor of inter-ethnic relations in the context of deepening the processes of integration and globalization is increasingly acquiring the nature of a mechanism for stabilization of social development, expanding of channels of international relations, formation of a new communicative space of modern civilization.

Awareness of historically determined factors makes us understand that it is the language that is becoming the basis of any culture, which is the main aspect in strengthening of multinational, social and political and cultural links among different nations.

Humanitarian cooperation is one of the most important elements of interaction, allowing using a human factor in multinational relations to the full extent. Its main task is the further development of joint educational, scientific, information and cultural projects.

One of the main ways of intensifying the learning process is using, to full advantage, information computer technologies as an open distributed system of continuous person-centered, high-quality, efficient education, organized by means of Internet multimedia in the research and educational environment $[1,9]$.

\section{Main contents}

\subsection{Advantages and Disadvantages of MOOC}

The ideas of open education have become widespread for the last few years. A surge of interest in open online learning is associated with the work done within the framework of federal competitions "Modern Digital Educational Environment in the Russian Federation" and with changes in the state policy in the field of education, which considers the development of the quality of online learning to be a priority.

A means of development of open learning is massive open online courses. Nominally, there are two types of MOOC - connectivist MOOC (or cMOOCs) and Stanford MOOC (xMOOC). The first courses, as the name implies, are based on the concept of connectivism in pedagogy, where educational autonomy, interactivity, openness, diversity, etc. are dominant factors. The educational philosophy of the second type of MOOC is closer to the classical model of education and is based on video lectures. A review of literature allowed us to highlight the following advantages and disadvantages of MOOC. The main advantages of MOOC, in our opinion, are:

1. Accessibility. MOOCs can provide greater accessibility, greater capacity for attracting learners, as well as development of the concept of lifelong learning. At present, MOOCs are able to provide a low barrier to entry, a free flexible schedule without initial requirements for participation [8]. Such conditions can be especially attractive for low-income families or students from countries where education is hard to access for a variety of reasons.

2. Widespread students' engagement. The main goal of MOOC is to attract students, to improve their academic progress, to expand their educational practice [8].

3. Implementation of continuing education principles. MOOC encourages the system of continuing education, lifelong education, making a student think about the goals and significance of his own learning and getting education. MOOC provides an effective tool for maintaining adult learners' competitiveness [4].

\footnotetext{
* Corresponding author: moodelfree $@$ yandex.ru
} 
However, it is worth noting a number of problems and issues that arise when using MOOC and, in particular, xMOOC.

1. Lack of individual training. The name MOOC itself means the necessity to include a large number of students. To some extent, such characteristics are contrary to the goals of individual learning. The proposed solution of this problem is software development, that is, using of computers for collecting and analyzing data about individual educational needs and opportunities and then constructing the information environment to meet students' needs better [7].

2. A high percentage of self-exclusion. D. Cornier and G. Siemens, point out that the problem of early termination of participation in MOOC is the most serious [3]. R. Meyer reports that only $7 \%$ of the total number of students of his course on Coursera have completed their studies in full [7]. As a rule, only $10 \%$ of MOOC participants acquire all the required types of training activities. Compared to traditional courses, such a high percentage of expulsion looks terrifying. One of the reasons for a high percentage of refusal from MOOC is the novelty of such courses, which attracts a certain number of curious teachers and students from other institutions. Besides, despite a high percentage of students' left-out, the overall goal of MOOC can be achieved by a relatively large number of course participants.

3. The high cost of creating MOOC. It is estimated that creating an $\mathrm{xMOOC}$ course will take an average of 100 hours and 10 weeks (8-10 hours per week to create a course). In money terms the cost of designing xMOOC is estimated at 15 000-30000 US dollars [7]. As a rule, MOOCs are created by teachers in their own free time. It may cause a decrease of responsibility and attention to their own professional activities.

4. Payment. Tuition fees create contradictions in MOOC philosophy: if the course is paid, how can it be called "open"? In addition, even the nominal price can significantly reduce the interest in the course.

5. Digital competence of teachers and the uncertainty of MOOC philosophy. A number of researchers call the information of designing a MOOC course by some teachers without any help a myth. Designing a MOOC course requires the engagement of a wide range of specialists. Otherwise, there is a high probability the course being designed will be of low quality.

A number of researchers oppose the statement that MOOCs are the embodiment of new pedagogy. T. Bates, in particular, [2] notes that at present the teaching methods used by xMOOC are based on old and outdated behavioral pedagogy which relies primarily on the transfer of information. According to him, MOOC are considered to be poor-quality forms of education suitable only for unpretentious students and the goals of expanding the boundaries of higher education on the basis of XMOOC remain ephemeral.

6. $\mathrm{xMOOC}$ is a form of promotion of corporate interests. This, perhaps, is one of the main fears of MOOC development. Indeed, if XMOOC is promoted by corporations, then there is a possibility that widespread introduction of MOOC will eventually lead to the homogenization of higher education, loss of academic freedom, and at the worst, dismissal of a large number of academic teaching staff members and their replacement by tutors that are called «Superprofessors» [10].

\subsection{Designing of blended learning at Kursk State University}

The ideas of open education have become widespread for the last few years. A surge of interest in open online learning is associated with the work done within the framework of federal competitions "Modern Digital Educational Environment in the Russian Federation" and with changes in the state policy in the field of education, which considers the development of the quality of online learning to be a priority.

The development of ideas of open teaching subjects can provide greater accessibility, greater capacity for attracting of learners, and also makes it possible to expand educational activities up to state-by-state level in the field of teaching the Russian language.

In this area the philologists of Kursk State University set a goal to develop and test the concept of a personalized massive open online course "Modern Russian language (section "Morphology") with elements of historical commentary "as a key element of a blended (online and offline) advanced training model in the framework of the project "Designing and implementing of a blended model (online and offline) based on massive open online courses, during advanced training of Russian language teachers and teachers of other academic subjects, conducting classes in the Russian language at Russian and foreign schools".

To achieve this goal it was necessary to solve the following tasks:

- expanding the availability of the Russian language learning (also outside the Russian Federation) through the use of open education technologies;

- development of a global market of educational services based on a flexible non-linear path of the professional development of the Russian language teachers and operating in the information and communication environment;

- designing of the basic course "Modern Russian language (section "Morphology") with elements of historical commentary" to assist Russian language teachers, as well as teachers conducting classes in the Russian language at Russian and foreign schools;

- rendering of methodological assistance in the development of students' independent training skills in the framework of improving the all-Russian blended (online and offline) model of advanced training in the Russian language;

- helping teachers of the Russian language, as well as teachers, conducting classes in the Russian language at Russian and foreign schools understand factual knowledge of the modern Russian language;

- designing, testing and implementation of personalized massive open online courses on the Russian 
language as part of the development of a system using special distance technologies.

The designed project has a social and public, a scientific and pedagogical significance.

The social and public significance of the project lies in the fact that language is a phenomenon of the spiritual culture of mankind, one of the forms of social consciousness. Firstly, the language, along with psychophysiological ability to reflect the world, is a prerequisite of social consciousness. Secondly, the language is a semantic foundation and a universal shell of various forms of social consciousness. By its contents the semantic system of the language is closest of all to ordinary consciousness. A specifically human form of transmitting of social experience (cultural norms and traditions, natural-science and technological knowledge) is carried out by means of the language.

The scientific and pedagogical significance was determined by the construction, reasoning and implementation of a personalized massive open online course model designed on the basis of using historical facts as a commentary on modern language processes in the field of morphology, explaining the internal logic and condition of currently existing linguistic phenomena; by developing and testing the concept of structuring educational video material based on storytelling and longreades; by improving a blended (online and offline) advanced training model.

The project "Designing and implementing of a blended model (online and offline) based on massive open online courses during advanced training of Russian language teachers and teachers of other academic subjects conducting classes in the Russian language at Russian and foreign schools" was carried out in the following areas:

I. Designing and implementation of the professional program of advanced training of the Russian language teachers "Historical commentary at the Russian language classes (section "Morphology")".

This course consists of two parts: a subject online course and a methodological offline course.

The leading ideas of the model:

- a combination of unification and variability in the structure of professional advanced training programs using a modular network-centered organization of the learning process;

- product-oriented assessment of the educational results of professional advanced training programs acquisition;

- developing of students' skills of personal management knowledge through the use of network communication and search methods, analysis and synthesis, combination, forecasting, modeling, etc. to update the contents of their subject area;

- development of students' ability to create personal educational environment and use its unified options.

The model presented by us implies the use of a personalized blended educational process responding to the needs of a professional advanced training program customer with the application of massive open online courses. The model is expected to provide an informal support during and after completion of training [3, 4]. The variable structure of the system is determined by a range of modules of the professional program. They allow achieving targeted training and building of a continuous, consistent personal route of professional development depending on the experience gained in teaching and research activities $[2,7]$.

II. Designing of a video lecture model. The central problem of designing a video lecture model is students' engagement $[5,8]$. Engagement or interaction time is time evaluation which a student spends on watching a video (i.e. the duration of a video viewing session). Engagement depends on the length of the video clip. Usually the watching time of an explaining video clip slows down after 4-6 minutes of watching, the watching time of a screencast slows down after 8 minutes of watching. Thus, the duration of the training video clip should not exceed 6-8 minutes.

Network approach is the methodological grounding for considering engagement or interaction time as a basis for classification. The peculiarity of the network approach is not to consider the subjects of the educational process, their qualities or properties, but to consider the goals or links that form between them. The structure and nature of links are taken as the key properties of the elements forming them. These key properties determine the participant's place of interaction among others, as well as his identity. The use of Educational Data Mining, a method of researching database applied for making decisions in the sphere of education is challenging.

Engagement is indirectly dependent on the format of the training video clip and the model of educational material presentation. Philip J. Guo, Juho Kim, Rob Rubin studied students' interaction in massive open online courses. The results of their research are given below [6].

1. Interaction of students with a training video clip is higher in shorter video clips.

2. "Talking head" (close-up presentation of a lecturer) is more attractive compared to a voiced presentation or screencast.

3. The high cost of video production does not matter, but the recording studio has minimum requirements for equipment:

- microphones and external sound cards for their use with a computer;

- background or chromakey;

- studio light boards or other lighting devices;

- a teleprompter and a number of others.

4. The training video in the style of Khan (i.e. during the explanation a teacher draws on the tablet) is more attractive.

5. Pre-planning of a training video clip improves interaction with it. Planning means a logical division of material into a series of small video lectures. Each video clip is a logically completed piece of content.

6. Speech rate affects the interaction with a training video - the quicker it is, the attractive the video is. However, emotional speech is more important than pace. 
7. Students interact with video lectures and tutorials (video instructions) in different ways [4].

III. Designing and testing of a model of educational material using storytelling and information and communication technology is creation of a "history myth" aimed at meeting educational needs through communication.

This area includes two components: the designing and implementation of an educational video model based on storytelling and the designing and implementation of a supportive notes model in the form of a multimedia longread, a kind of storytelling, which consists of a combination of text and illustrations. This approach allowed us to overcome information overloading by using nativeness; to improve the apprehension of educational material by including pedagogical hermeneutics; to use various channels of information presentation - audio, video, text; to activate the processes of cognition [10].

IV. Designing of a basic online course "Modern Russian language (section "Morphology") with elements of historical commentary", built on a choice from a huge amount of historical data accumulated and systematized by science and from basic information that helps a teacher in his work and increases the level of his linguistic training.

The basic course allowed one to link the study of the contemporary state of the Russian language, its morphological system with the facts from the history of the Russian language; to establish the relationship between the ancient Russian language and the modern Russian language; to help a teacher explain to students the origin and nature of a modern language phenomenon in an accessible form; to bring up through the subject a harmoniously developed person, capable of deep and unconventional thinking, of connecting together the knowledge acquired, of orienting in historical and modern linguistic processes.

V. Designing of special distance learning technologies in the basic course "Modern Russian language (section "Morphology") with elements of historical commentary" includes several special distance learning technologies:

- stratification (differentiation) of the student body which implies introductory testing to determine the level of students' preparedness and the goals of acquiring the course. The test is necessary for the formation of differentiated groups of students;

- differentiation of educational material, implying its level composition;

- students' independent development of the content: implementation of individual educational projects that contribute to a deeper acquisition of educational material, development of information literacy, reducing time and efforts of teachers to find relevant information;

- pedagogical support, required by the student, with the help of webinars (method of a reverse dialogue).

VI. Creating of a propaedeutical course "Using ICT in educational activities of the Russian language teacher" aimed at developing independent learning skills through open learning, the goal of which is not only to familiarize students with effective independent learning techniques, but also to develop project work skills using ICT-infographics, timeline, interactive posters, etc.

This project has made it possible to achieve targeted training and creating of a continuous, consistent personal route of professional development, depending on the experience acquired in teaching and research.

\section{Conclusion}

Active work aimed at the implementation of models of massive open online courses on the Russian language: "Practical Russian language course (Orthography. Punctuation. Connected country specific texts)"; "Practical course of the Russian language on the basis of local lore texts", "Linguistic and verbal analysis of local lore texts", "Linguistic and local lore material for studying philological subjects", "Connected local lore texts at the Russian language classes", "Modern Russian language (section "Morphology") with elements of historical commentary" and others is being carried out at Kursk State University. This work contributes to the formation of a professional information culture, ICT competencies in a two-level training of a philology teacher.

\section{References}

1. Letapurs T.V., Malykhina T.M., Kharitonov V.I. Scientific notes of Kursk State University. Kursk: Publishing Kursk State University. Activation of the process of teaching Russian language and speech culture based on information technologies. №1 (2). 192-199 (2005).

2. Bates T. What's right and what's wrong about Coursera-style MOOCs. Retrieved from: http://www.tonybates.ca/2012/08/05/whats-rightand-whats-wrong-about-coursera-style-moocs (2012)

3. Cormier D., Siemens G. EDUCAUSE Review Through the open door: open courses as research, learning, and engagement.. 45(4): 30-9. (2010).

4. Daniel, J. . Journal of Interactive Media in Education. Making sense of MOOCs: Musings in a maze of myth, paradox and possibility 3, 1-20 (2012).

5. Falvo D. A., Solloway S. Tech Trends: Journal of the Association for Educational Communications and Technology, Constructing community in an online course. 48(5), 56-64 (2004).

6. Guo P.J. Kim J, Rubin R. Proceedings of the first ACM conference on Learning@ scale conference. Atlanta, Georgia. How Video Production Affects Student Engagement: An Empirical Study of MOOC Videos. 21-30 (2014).

7. Meyer R. The Atlantic. What it's like to teach a MOOC (and what the heck's a MOOC?). (2012) Retrieved from: http://bit.ly/2PbRxJr (2012)

8. Siemens, G., \& Downes, S. Good MOOCs, Bad Moocs. Retrieved from: 
http://chronicle.com/blogs/brainstorm/tag/udacity (2013)

9. Zolotykhin S.A. Life Science Journal. Informal media learning development through Web 2.0, 11. 8s. 186189 (2004).
10. de Waard I., Abajian S., Gallagher M. S., Hogue R., Keskin N., Koutropoulos A., Rodriguez O.C. International Review of Research in Open and Distance Learning, Using mLearning and MOOCs to understand chaos, emergence, and complexity in education. 12(7), 94-115 (2011). 